\title{
DAS ARMAS ÀS URNAS: A PARTICIPAÇÃO DOS CORONÉIS DA BAHIA NA REVOLUÇÃO DE 1930
}

From guns to ballot boxes: the role of coron els from Bahia in the Revolution of 1930

De las armas a las urnas: la participación de los coroneles de Bahía en la Revolución de 1930 


\title{
RESUMO
}

Este artigo discute a participação dos coronéis do interior da Bahia na Revolução de 1930, desde a campanha da Aliança Liberal até a centralização do poder federal no estado, sob o governo de Juraci Magalhães, no ano de 1933. Com base na análise de cartas, telegramas e jornais da época, demonstra-se como esses homens do interior, que antes conduziam com armas sua atuação política, na Primeira República, passaram a utilizar as urnas após a vitória do movimento revolucionário de outubro de 1930, num constante processo de acomodação política que marcou o governo Vargas na Bahia.

PALAVRAS-CHAVE: Revolução de 1930; Bahia; Oligarquias.

\begin{abstract}
This paper discusses the role of colonels from the inland cities of Bahia in the Revolution of 1930, from the Liberal Alliance campaign to the centralization of federal power in the state, ruled by Juraci Magalhães, in 1933. Based on the analysis of letters, telegrams, and newspapers of the time, it demonstrates how these men from the countryside went from using guns, in the First Republic, to ballot boxes after the success of the revolutionary movement of October 1930, showing the constant process of political accommodation that characterized the Vargas government in Bahia.
\end{abstract}

KEYWORDS: Revolution de 1930; Bahia; Oligarchies.

\section{RESUMEN}

Este artículo analiza la participación de coroneles en el interior de Bahía en la Revolución de 1930, desde la campaña de la Alianza Liberal hasta la centralización del poder federal en el estado, bajo el gobierno de Juraci Magalhães, en 1933. Basado en el análisis de cartas, telegramas y periódicos de la época, se demuestra cómo la acción política de estos hombres del campo, liderados por las armas, en la Primera República, fue reemplazada por las urnas, tras la victoria del movimiento revolucionario de octubre de 1930, en un proceso constante de acomodación política que marcó al gobierno Vargas en Bahía.

PALABRAS CLAVE: Revolución de 1930; Bahía; Oligarquías. 


\section{INTRODUÇÃO}

a madrugada de 24 de outubro de 1930, a chamada Primeira República (1889-
1930) chegava ao fim no Brasil. 0 movimento que deslocou as tradicionais oligarquias do epicentro do poder (Ferreira; Pinto, 2014: 408) é frequentemente revisitado, tanto para compreender a abordagem do tema no debate intelectual da época (Oliveira, 1978) e as transformações que ocorreram na sociedade e no Estado após a ascensão de Getúlio Vargas ao Executivo, quanto para entender as razões que levaram grupos heterogêneos a recorrer às armas para derrubar o situacionismo (Fausto, 1995), tal como analisa este artigo, ou, ainda, questionar o acontecimento como marco de ruptura da história política do país (De Decca, 2004).

Antes de 1930, a distribuição desigual do poder conferia aos estados uma diferenciação em termos de organização política e econômica. Entre os seis estados mais fortes, São Paulo, Minas Gerais, Rio Grande do Sul, Rio de Janeiro, Pernambuco e Bahia - que reuniam bancadas numerosas e/ou economias relativamente autossuficientes - , havia um pacto oligárquico cuja estabilidade era frequentemente comprometida, dadas as alianças e acomodações feitas e desfeitas ao sabor das circunstâncias. Pela fragilidade, a renovação do pacto político entre esses estados, que ocorria a cada sucessão presidencial, não foi capaz de assegurar a longevidade da Primeira República, que se esgarçou completamente ao longo da década de 1920 (Viscardi, 2019: 52-59).

Assim, o lugar da Bahia em 1929, quando se organizava no Brasil a Aliança Liberal para concorrer com a chapa Getúlio Vargas/João Pessoa às eleições majoritárias contra Júlio Prestes/Vital Soares, era de relativo destaque. Além de ocupar um dos ministérios do governo de Washington Luís (1926-1930), a Bahia barganhou o posto da vice-presidência na sucessão do Executivo. 0 pacto político que a colocava ao lado do Catete foi forjado com o sacrifício das rivalidades entre as principais lideranças estaduais. Ratificado em 1930, na Convenção dos Municípios, o acordo não se mostrou capaz de neutralizar todas as fissuras existentes entre as oligarquias, de modo que, passadas as eleições, quando despontou 0 movimento revolucionário em 3 de outubro de 1930, havia no estado grupos que se alinhavam em campos opostos.

Na Bahia, o movimento revolucionário foi organizado sob três perspectivas: a primeira, sob orientação de Juarez Távora, envolvia principalmente os militares; a segunda, sob orientação e apoio de conspiradores do Rio de Janeiro, abrangia principalmente civis, a exemplo de Antônio Maciel Bonfim, que veio a ser secretário do Partido Comunista; a terceira, sob controle das oligarquias baianas do interior e apoio do governador de Minas Gerais (Batista, 2018: 23). 
Ao que parece faltou uma ação coordenada entre esses núcleos de conspiração para que o movimento fosse bem sucedido, razão pela qual a Bahia pareceu estar, até o desfecho do movimento, em completa solidariedade com a ordem constituída (Sampaio, 1998: 224).

Apesar das aparências, cartas, telegramas e jornais do período revelam intensa movimentação à margem da legalidade e testemunham a participação dos coronéis do interior na conspiração. Com relevante papel, pela quantidade de eleitores de que dispunham e que definiam os resultados dos processos eleitorais, eram esses coronéis que davam sustentação política às agremiações partidárias na Bahia. Além do quadro de eleitores, controlavam a economia, ocupando importante lugar na balança comercial do estado, que dependia ainda da produção agrícola dos municípios. Impactados pela Crise de 1929 e pela soma de impostos cobrados pelo governo, não havia motivos para recusar, por completo, uma plataforma liberal que prometia solução para as suas inquietações.

Com a vitória revolucionária, abriu-se um longo caminho para a recomposição dos poderes, que na Bahia passou pelo desarmamento e desgaste de alguns redutos coronelistas. As relações marcadas por numerosos conflitos que se estenderam por toda a década de 1920 entre o governo estadual e a política local foram alteradas, promovendo-se a institucionalização entre essas esferas de poder, por meio da inserção dos chefes políticos locais nas agremiações partidárias. 0 recurso às armas, usual na república deposta, deu lugar a outras formas de combate, entre elas a disputa do poder por meio das urnas.

\section{OS CORONÉIS E A CAMPANHA PELA ALIANÇA LIBERAL NA BAHIA}

$P$ ara Consuelo Sampaio (1998: 205-218), a campanha pela sucessão presidencial em 1930 quase não despertou interesse na Bahia, ficando à sombra da campanha para sucessão do governador do estado, que ameaçava pôr fim à acomodação estabelecida por acordos recentes entre as principais lideranças políticas regionais. No plano nacional, não havia razões para as elites políticas aderirem a um movimento que ameaçava destituir do poder os seus membros mais representativos (Silva, 2011: 23). Assim, como o situacionismo não dispensou a devida atenção à campanha para as eleições presidenciais de março de 1930, deixou o campo aberto para a atuação da oposição.

0 ex-governador José Joaquim Seabra (1877-1942), que esteve à frente do Executivo estadual entre 1912 e 1916 e 1920 e 1924, esforçou-se em divulgar o programa aliancista na capital e em alguns dos municípios do estado. Alijado do poder desde o término do governo, em função de sua vinculação com a Reação Republicana, quando foi candidato à vice-presidência na chapa encabeçada por Nilo Peçanha, em 1922, que perdeu as eleições 
para Artur Bernardes, Seabra aderiu à plataforma da Aliança Liberal, em 20 de setembro de 1929. Participou, como representante da Bahia, da convenção nacional destinada a indicar os candidatos liberais à presidência e à vice-presidência da República, respectivamente Getúlio Vargas e João Pessoa, e foi também escolhido presidente honorário da comissão executiva da Aliança Liberal (Batista, 2018: 520).

Na Bahia, a campanha da Aliança Liberal foi intensificada no mês que antecedeu as eleições. Segundo informações veiculadas em 6 de fevereiro de 1930, no jornal carioca Correio da Manhã, que apoiou a Aliança Liberal, os primeiros discursos foram realizados em Salvador, nos dias 5 e 6 de fevereiro daquele ano. 0 tempo demasiadamente curto para realizar comícios em todos os municípios levou a uma divisão dos caravaneiros aliancistas no estado. De um lado, cobrindo a zona do São Francisco, ficaram responsáveis os aliancistas Carlos Machado e Dário Crespo, deputados do Rio Grande do Sul, que viajaram por toda a região em trem especial ao lado de representantes baianos, a exemplo de Nelson Carneiro. De outro, José Joaquim Seabra, que ao lado de João Neves excursionou por diferentes cidades, a exemplo de Ilhéus, Cachoeira, São Félix, Itabuna, Feira de Santana e também Juazeiro e Alagoinhas.

Além das caravanas oriundas da capital, havia uma mobilização em prol da Aliança Liberal por iniciativa de alguns coronéis do Vale do São Francisco. 0 programa liberal encontrou sustentação em lideranças políticas do interior e, entre as razões para isso, localizam-se as disputas regionalistas. 0 desequilíbrio entre os estados, com a força excessiva de uns ameaçando absorver os demais, figura como um dos principais fatores explicativos da crise política e econômica de 1929 e como lastro do movimento aliancista e revolucionário de 1930 (Lima Sobrinho, 1975: 54).

0 ano de 1930 revelaria esse desequilíbrio entre os estados da Bahia e de Minas Gerais. Na Bahia, o conflito começou com a disputa eleitoral no município de Carinhanha, no sudoeste do estado, e evoluiu rapidamente para um violento confronto com o estado vizinho. Em fins de 1928, quando o segundo mandato de intendente do coronel João Duque expirou, ele concorreu ilegalmente a um terceiro. Como ele mesmo era o presidente da junta eleitoral que confirmava as eleições, não foi difícil reconhecer a sua própria vitória. 0 reconhecimento foi rejeitado por Vital Soares (1874-1933), governador da Bahia entre 1928 e 1930, que concedeu a vitória, atestada pelo Senado baiano, ao rival, coronel João Alkimin (Pang, 1979: 198-200).

João Duque não aceitou a intervenção do governo baiano, tentando impedir a posse do coronel Alkimin e, junto a alguns aliados de Minas Gerais e da Bahia, a exemplo de Franklin Lins de Albuquerque, Pilão Arcado e Chico Leóbas, de Remanso, abriu luta contra o 
governo e seu protegido. Por outro lado, Alkimin também recorreu aos parentes do norte de Minas Gerais e aos amigos na Bahia. Assim, a luta extrapolou as fronteiras do estado e serviu como uma espécie de termômetro para as eleições presidenciais, uma vez que os governadores dessas unidades federativas apoiavam candidatos diferentes e queriam mostrar a sua força política sobre o Vale do São Francisco (Pang, 1979: 198-200).

No jogo político das oligarquias estaduais, seria uma derrota para Vital Soares o fato de Duque e seus companheiros mineiros derrotarem Alkimin. Cabe lembrar que a eleição de Antônio Carlos em Minas Gerais (1926-1930) marcava uma renovação na política, pois ele defendia uma plataforma de governo que passava, necessariamente, por mudanças nas regras eleitorais (Viscardi, 2019: 299). Portanto, em termos políticos, o presidente de Minas Gerais confrontava-se abertamente com o da Bahia, aliado do governo central.

Entre novembro e dezembro de 1929, diversas cartas foram trocadas entre Vital Soares e Antônio Carlos. A imprensa de ambos os estados repercutiu o conflito. Em apoio ao governo da Bahia, o presidente Washington Luís teria ordenado a um representante da Procuradoria Federal que indicasse João Duque, Franklin e Leóbas como culpados de um crime que ocorreu em Carinhanha. Com a indicação, a Força Pública de Minas Gerais retirou João Duque da Bahia. Dado o apoio do governo mineiro ao grupo de João Duque, Vital Soares empregou a Força Pública para punir os coronéis daquela região, razão pela qual esse homens não precisaram de muita persuasão para apoiar a Aliança Liberal, que chegaria à Bahia apoiada por Seabra, ao final de 1929 (Pang, 1979: 198-200).

Assim, as dissidências regionais eram fortalecidas pelas dissidências oligárquicas entre os estados. Minas Gerais, por exemplo, tinha o objetivo de golpear a hegemonia da oligarquia cafeeira do estado de São Paulo, apoiada pela Bahia. Além das disputas regionais, o conhecido descontentamento de uma parcela de produtores e comerciantes diretamente atingidos pela Crise de 1929 era razão suficiente para justificar o alinhamento de chefes municipais da Bahia com a Aliança Liberal. Nos primeiros meses de 1930, esse desentendimento foi largamente divulgado pela imprensa (Batista, 2018: 83).

0 descontentamento das oligarquias passou à conspiração. Com a vitória de Júlio Prestes/Vital Soares, o cenário político ganhou novos contornos. Nos bastidores, os coronéis armavam seus jagunços, os militares conspiravam com os Tiros de Guerra, e o governo empenhava-se em organizar a resistência com a Força Pública do Estado, ponto estratégico tanto para os aliancistas quanto para o governo central, pois ligava os estados do Nordeste aos do Centro-Sul, ligação esta fundamental para que o movimento ou a sua contenção tivessem sucesso. 


\section{A CONSPIRAÇÃO REVOLUCIONÁRIA DOS CORONÉIS NA BAHIA}

$\mathrm{C}$

onforme veiculado pela imprensa, a exemplo da edição de 4 de maio de 1930 do jornal carioca $A$ Batalha, que se prestava à oposição baiana como espaço de denúncia na capital do país, tão logo os resultados eleitorais de março começaram a ser divulgados, numerosas contestações foram encaminhadas aos juízes acusando o pleito de mais uma fraude, mesmo após o reconhecimento da esmagadora vitória da chapa Júlio Prestes/Vital Soares. Com o resultado, os políticos da Bahia ligados à situação ocuparam-se em definir o candidato a futuro governador. É provável que os grupos que estiveram à frente da Aliança Liberal no estado tenham sido sondados a participar do movimento de conspiração revolucionária nesse período, pois, indiferentes aos resultados das urnas, ou muito motivados por eles, os aliancistas e os militares continuavam conspirando.

$\mathrm{Na}$ Bahia, as primeiras conversas sobre o movimento armado que estava sendo organizado no Sul e no Sudeste do país deram-se no mês de fevereiro de 1930, durante a passagem dos tenentes Juraci Magalhães, Jurandir Bizarria Mamede e Agildo Barata por Salvador, quando de suas transferências do Rio de Janeiro para a Paraíba, portanto, antes mesmo do pleito eleitoral. Além de Seabra, receberam apoio dos médicos Eduardo Bizarria Mamede e Átila do Amaral e dos engenheiros Alípio Viana e Leopoldo Amaral, que havia presidido o Comitê da Aliança Liberal na Bahia (Tavares, 2008: 381-382).

No âmbito militar, assumiu a liderança do movimento o tenente Joaquim Ribeiro Monteiro, que era sergipano, mas estava àquela época servindo no $19^{\circ}$ Batalhão de Caçadores, em Salvador. As instruções de Juarez Távora, responsável pelo levante no Nordeste do país, chegavam por meio de contatos telegráficos, cartas e de Eduardo Bizarria Mamede, que viajava regularmente à Paraíba para colher informações. Essas cartas foram compiladas em importante obra organizada por José Calasans. De fevereiro a maio de 1930, os contatos foram recorrentes, e, nas missivas enviadas ao líder do movimento na Bahia, Joaquim Monteiro esclarecia questões referentes ao momento político, buscando, nas contradições e na degradação da República brasileira, as justificativas para a organização do movimento (Silva, 1981).

Nessas cartas, Joaquim Monteiro revelava o quão difícil e perigosa era a associação com civis no estado. Uma das razões era o seu desconhecimento acerca das lideranças locais, uma vez que era de Sergipe e não mantinha relações políticas na Bahia. Ainda assim, pela análise que fazia da conjuntura, julgava que na Bahia seria bem acolhido o movimento no meio civil (Silva, 1981).

Seguindo instruções recebidas de Juarez Távora, Joaquim Monteiro deveria preparar a Bahia para neutralizar a influência do governo central em toda a zona que se estendia da Bahia até o extremo do Nordeste, impedindo por todos os meios que ele retirasse de lá quais- 
quer recursos bélicos para reforçar a sua defesa contra a operação do Centro-Sul (Silva, 1981). Havia, no entanto, a previsão de que poucos núcleos militares se disporiam a tal movimento.

Quanto aos civis, esse número era ainda mais reduzido. Se já estava difícil reuni-los na conspiração revolucionária, com o afastamento de Luís Carlos Prestes dos tenentes que apoiavam o movimento, em maio daquele ano, o próprio articulador da revolução da Bahia, o tenente Joaquim Monteiro, considerou a possibilidade de descontinuar as articulações, abrindo um intervalo de conversas com Juarez Távora. Antes, porém, passou-lhe informações acerca das ligações feitas dentro do estado.

Como se observa das missivas, as ligações entre militares e civis eram subterrâneas. Joaquim Monteiro afirmava ter sido apresentado a dois civis de confiança absoluta na Bahia: "um chefe sertanejo podendo dispor de cerca de 500 homens (segundo informações que necessitavam ser confirmadas por um agente de confiança) e outro contando com elementos esparsos na capital" (Silva, 1981). Segundo indicou, o primeiro era ligado a Seabra, e o segundo a Moniz Sodré, dois nomes que defenderam a Aliança Liberal na Bahia.

A indicação da existência de dois chefes sertanejos envolvidos na conspiração cobra uma reflexão sobre a atuação política de algumas lideranças do interior. No período, Horácio de Matos (1882-1931), das Lavras Diamantinas, e Franklin Lins de Albuquerque (18811944), de Pilão Arcado, estavam entre os coronéis de maior prestígio na Bahia, por conta de suas atuações na Revolta Sertaneja, que ocorrera em 1919 (Batista, 2018: 53).

No ano de 1915, quando enfrentava dificuldades para exercer seu mando no interior da Bahia, Seabra promoveu uma reforma na Constituição Estadual e passou a usar a nomeação dos intendentes como forma de concentrar poder em suas mãos. 0 município era a base de poder do coronel (Leal, 2012), e a reforma provocou reações, levando a sérios conflitos entre as forças políticas locais e a Força Pública da Bahia. 0 presidente Epitácio Pessoa (1919-1922) interveio, encaminhando emissários que negociaram diretamente com os coronéis. Estes, por sua vez, só cessaram fogo após assinarem acordos vantajosos, que lhes garantiram domínio sobre amplas regiões (Sarmento, 2011: 180).

0 prestígio adquirido pela Revolta Sertaneja foi intensificado com a passagem da Coluna Prestes na Bahia. 0 movimento tenentista sufocado em 1922 ressurgiu em 1924, em reposta ao autoritarismo do governo de Artur Bernardes (1922-1926). Em março de 1926, atravessou as fronteiras da Bahia, onde batalhões civis foram subvencionados pelo governo federal para combatê-lo. Do contingente reunido, os batalhões de Horácio de Matos e Franklin Lins de Albuquerque foram os mais afamados pelo papel que tiveram na perseguição aos revoltosos (Melo, 1989: 105-117). Com esse prestígio, a balança do poder na Bahia só poderia ser equilibrada com o reconhecimento dessas forças que atuavam no 
interior, e isso justifica os recorrentes conflitos com o Executivo estadual ao longo dos anos vinte (Sampaio, 1998: 199).

Não se sabe exatamente se Franklin Lins era o chefe sertanejo indicado por Monteiro nas cartas endereçadas à Bahia. Apesar de não parecer que ele mantivesse relações de subordinação com Seabra, é conhecida a sua atuação em favor dos revoltosos (Batista, 2018: 57). Além dele, outros nomes podem ser elencados: João Duque, de Carinhanha, Rotílio Manduca, de Remanso, Durval Marinho Paes, de Angical, Deraldo Mendes, de Vitória da Conquista, Mário Teixeira, de Caetité, e o coronel Rabelo, de Bom Jesus da Lapa, foram coordenados pelo coronel Herculano Leite, da Força Pública de Minas Gerais, nas atividades relacionadas à conspiração. A estratégia do governo mineiro ao cooptar as oligarquias da Bahia consistia em enviar Franklin Lins e seu exército para Salvador, a fim de tomar o governo do estado, enquanto Duque desceria lentamente o rio para acabar com os focos de resistência de coronéis recalcitrantes (Pang, 1979: 204).

A defesa de Minas Gerais também dependia da guarnição das fronteiras com a Bahia. Em testemunho sobre a organização dessa defesa, Virgílio de Melo e Franco assegurou que Mário Brant e Odilon Braga, secretário de Segurança Pública, trabalhavam na capital de Minas Gerais "articulando o movimento não só dentro do estado como também no sertão da Bahia, por intermédio dos chefes João Duque e Rotílio Manduca" (Franco, 1980: 67).

\section{ÀS ARMAS: OS CORONÉIS EM DEFESA DA REVOLUÇÃO DE OUTUBRO DE 1930}

o dia 3 de outubro de 1930, o movimento revolucionário irrompeu no Sul do Brasil.
Onze dias depois, o jornal carioca Correio da Manhã veiculou informações sobre o combate que o governo federal vinha fazendo às investidas dos revoltosos na Bahia. Entre as ações, destacava-se a arregimentação de coronéis que deveriam ocupar o norte de Minas Gerais para impedir o avanço dos revolucionários mineiros sobre o Rio de Janeiro. Havia tempos que o presidente desconfiava que os mineiros estavam usando o porto de Caravelas, na Bahia, para importação de armas. A invasão seria coordenada por Francisco Rocha, e os civis, em sua maioria, liderados por Horácio de Matos, que no dia 8 de outubro teria recebido um pagamento de seis contos para as despesas militares (Pang, 1979: 208).

Porém, com as sucessivas vitórias dos revolucionários nos estados do Nordeste, 0 plano de invasão a Minas Gerais foi cancelado, transferindo-se todo o aparato para conter as tropas dissidentes e resguardar a capital da Bahia. De acordo com informações veiculadas pelo 0 Jornal em $1^{\circ}$ de novembro de 1930, Ponta de Areia e Caravelas, no litoral sul da 
Bahia, haviam sido tomadas no dia 10 de outubro e estavam sob ordens de tropas mineiras desde então.

A região de Caetité e Guanambi, próximas a Minas Gerais, em pouco tempo também estariam sob o comando dos coronéis revolucionários. Mário Teixeira, agricultor e industrial daquela região, vinha mantendo contato com os políticos de Minas Gerais para criar as condições para a revolução sair vitoriosa no sudoeste do estado. Segundo revelou o Diário da Bahia em 20 de dezembro de 1930, os primeiros contatos foram realizados por Carneiro Baptista Neves, advogado de Caetité e professor de Guanambi. Por intermédio dele, Mário Teixeira procurou os mineiros Olegário Maciel, Artur Bernardes, Mário Brant e Cristhiano Machado, mantendo relações com eles por meio de cartas e telegramas para ajustar os pontos do assalto.

De acordo com relatos dos vitoriosos ao jornal, o primeiro assalto foi feito no dia 11 de outubro de 1930, quando Mário Teixeira ordenou ao capitão Ovídio Santos e a João Belarmino que fossem a Espinosa, na fronteira com Minas Gerais, portando cartas, a fim de estabelecer ligações entre as forças mineiras e a coluna do Nordeste. No dia 16 de outubro ocupou a estação telegráfica de Guanambi e marchou para Caetité. Ali, recebeu telegrama de Pedro Lago (1870-1958) pedindo que reconsiderasse o seu posicionamento e solicitando que combatesse em favor do governo. Negou. No dia 19, afirmou ter montado um Comando Geral em Guanambi, e. no mesmo dia, Carneiro Neves tomou Urandi, ocupando a estação telegráfica.

Paralelamente, Lindolpho Nunes tomava sem resistência o município de Monte Alto, Leite Filho ocupava Riacho de Sant'Anna, e o próprio Mário Teixeira telegrafava a João Duque e ao capitão Querino pedindo que tomassem Carinhanha e Bom Jesus da Lapa. De acordo com a matéria do Diário da Bahia, Anísio Teixeira teria ido a Guanambi em missão governamental para demovê-lo. Ao mesmo tempo, Mário Teixeira recebia ameaças de Horácio de Matos, que anunciava um ataque às suas tropas, mas seu plano para a tomada desses municípios foi executado sem objeções.

Em entrevistas divulgadas pelo jornal carioca Diário de Notícias em 26 de novembro de 1930, Agildo Barata e outros militares envolvidos no movimento deram informações a respeito do contingente que enfrentaram na Bahia. Para os entrevistados, eles enfeixavam cerca de 400 homens da polícia, 600 jagunços de Horácio de Matos e de Geraldo Rocha, num conjunto denominado Batalhão Patriótico das Lavras Diamantinas, e 180 praças do $21^{\circ}$ Batalhão que fugiram de Recife quando a revolução estourou.

0 compromisso de Horácio de Matos com Washington Luís era de formar seis batalhões, totalizando 3 mil homens até o final de outubro de 1930. No dia 18, um total de 500 homens chegava à cidade de Cachoeira, no Recôncavo, para serem incorporados às 
forças legalistas alojadas na cidade de Alagoinhas, que guarnecia a capital do estado, mas a promessa quanto à quantidade não pôde ser cumprida em função dos desentendimentos e receios que se fizeram presentes entre Horácio de Matos e os demais coronéis do interior (Pang, 1979: 210).

Franklin Lins de Albuquerque também enviou um contingente para Alagoinhas ao tempo em que seguia com mais 630 homens para Juazeiro. Diferentemente de Horácio de Matos, a sua posição era duvidosa. Não se tem certeza se ele servia ao governo, aos revolucionários ou a ambos, tendo em vista que foi um dos maiores recrutadores das hostes da Aliança Liberal e, por outro lado, hipotecou solidariedade ao presidente por meio de telegrama. Pang afirma que, para os revolucionários, a estratégia era que ele atacasse Salvador quando a cidade estivesse nas mãos da unidade avançada. Porém, em Alagoinhas, Franklin Albuquerque não entrou em luta com exército aquartelado, numa demonstração de que estava "negociando com os dois lados", visando obter vantagens de quem vencesse (Pang, 1979: 211).

Telegramas trocados entre Jurandir Mamede e Juarez Távora em 22 de outubro de 1930 revelam o avanço do movimento. As tropas lideradas por Juraci Magalhães chegaram às fronteiras do norte da Bahia. Um dia depois, Jurandir Mamede atravessou o São Francisco com destino a Juazeiro, e, na mesma data, seguia para Alagoinhas um batalhão de voluntários arregimentados por Gileno Amado em Itabuna (Arquivo Juarez Távora. FGV/CPDOC.JT dpf.1930.05.00). À medida que o governo da Bahia desistiu de atacar Minas Gerais, o que teria dispersado essas forças, elas dirigiram-se, coordenadamente, para Alagoinhas, onde após uma batalha ocorrida no povoado de Capianga, receberam-se notícias de que o presidente Washington Luís havia sido deposto, pondo fim às lutas (Pang, 1979: 213).

A posição dos coronéis do interior na tomada do estado da Bahia é controversa, pois aparece tanto ligada ao governo quanto aos revolucionários. João Duque, por exemplo, foi acusado mais tarde de ter recebido dinheiro para arregimentar jagunços, alguns dos quais presos em Alagoinhas. Apesar das contradições e do pragmatismo político dos coronéis que via de regra ficavam ao lado da situação, são notórias as ações subterrâneas e cautelosas em favor da Revolução de 1930. Conforme asseguramos, matérias veiculadas pelo Diário da Bahia entre os meses de julho e setembro daquele ano dão conta do descontentamento dos produtores do interior do estado em relação ao governo de Vital Soares (1874-1933), vice-presidente eleito, que manteve os impostos criados pelo ex-governador Góes Calmon (1924-1928) e ainda decretou a cobrança de novos. A lavoura e os produtores estavam no cerne da crise oligárquica da Bahia, que, em 1930, era essencialmente agrícola.

Não existiam no estado grandes empresas estrangeiras. Assim, a maior riqueza estava concentrada na agricultura, na pecuária e em pequenas indústrias distribuídas pelo interior 
do estado. Ainda que tivesse sofrido uma baixa crítica na produção do cacau, do fumo e do açúcar, os seus principais itens de exportação agrícola, era a produção nos redutos desses coronéis que mantinha a balança comercial favorável para o estado (Almanak Laemmert, 1930: 226-362).

Sob essa perspectiva, é possível desenhar um quadro da oligarquia baiana em dissenso e, diante disso, o acolhimento, de bom grado, de um movimento revolucionário que viesse a mudar o estado de velhas coisas e assegurar a permanência de outras. Havia razões numerosas para o congraçamento entre os revolucionários e essas forças produtoras do interior do estado.

\section{O DESARMAMENTO DOS CORONÉIS NA BAHIA}

$\mathrm{V}$ encida a revolução, as primeiras medidas editadas por Leopoldo do Amaral, primeiro interventor federal da Bahia (novembro de 1930 a fevereiro de 1931), determinaram, entre outras coisas, a extinção do mandonismo e do coronelato no interior. Seguindo as diretrizes revolucionárias, para o engenheiro aliancista, a depuração da oligarquia deposta só seria encerrada com a desarticulação de seus correligionários do interior. Assim, segundo publicação do jornal baiano A Tarde em 13 de novembro de 1930, era preciso desarmar os chefes locais, inclusive aqueles que teriam apoiado o movimento. Por essa razão, ao passo que tomava as medidas necessárias à organização administrativa do estado, os vitoriosos organizavam o combate e desarmamento dos coronéis do interior. Ainda no dia $1^{\circ}$ de novembro, data da posse de Leopoldo do Amaral (1893-1965), um representante já havia sido designado para mediar a entrega das armas de Horácio de Mattos. Começava assim a "profilaxia social dos sertões baianos" (Arquivo Juarez Távora. FGV/CPDOC.JT dpf.1930.05.00).

De novembro de 1930 a março de 1931, militares vitoriosos varreram o Médio São Francisco, desarmando e prendendo lideranças políticas locais (Lins, 1979: 18). Mesmo que o interesse fosse identificar as armas e o dinheiro usados para combater a revolução, bem como os homens beneficiados pelo governo de Washington Luís, desde os primeiros momentos da profilaxia social houve uma seleção. Não foi por outra razão que Juraci Magalhães, que secretariava Juarez Távora em suas atividades de vice-rei do Norte, questionou: "políticos marca Madureira Francisco Rocha devem ser deixados liberdade ou presos? [...] Julgo conveniente manter coronel Lopes dada sua profissão de fé revolucionária" (Arquivo Juarez Távora. FGV/ CPDOC.JT dpf.1930.05.00).

Juraci Magalhães assegurou estar agindo com excesso de tolerância, mas já havia pedido ao general Collatino a publicação de uma nota alertando que a tolerância não deveria ser interpretada como fraqueza. No processo de desarmamento, registraram-se mortes e al- 
gumas prisões, a exemplo da de Marcionílio Souza Tranquilino, do município de Maracás, de quem se apreendeu cerca de 5 mil armas entre revólveres, pistolas, fuzis, mosquetes e rifles e 70 mil tiros.

A situação de Horácio de Matos recebeu atenção especial. Segundo o coronel Facó, a opinião pública colocava Horácio de Matos em situação privilegiada. Por um lado, ele teria assumido o compromisso de depor as armas em caráter diplomático; por outro, alguns chefes sertanejos que assumiram o mesmo compromisso, como Franklin Lins de Albuquerque, Leóbas, Marcionílio Tranquilino e outros, estavam presos ou mortos, e a palavra dos vitoriosos passava a ser questionada. Segundo os oficiais, a autoridade de Horácio de Matos estava muito abalada, mas a sua prisão pelo compromisso assumido poderia ser vista como acoimada má-fé, com consequências graves antes do desarmamento de sua gente. A situação era delicada, pois não se cogitava a soltura dos presos, mas era preciso encerrar as negociações com Horácio de Matos, respeitando as cláusulas preestabelecidas, a fim de evitar uma convulsão social (Arquivo Juarez Távora. FGV/CPDOC.JT dpf.1930.05.00). 0 cenário era muito delicado, mas, no final de dezembro daquele ano, a situação com Horácio de Matos parecia resolvida, e ele publicou boletins convidando seus amigos para entregarem as armas no município de Lençóis. Após o desarmamento, Horácio de Mattos foi preso, vindo a ser assassinado em Salvador, em maio de 1931.

0 desarmamento enfraqueceu os coronéis do ponto de vista militar, mas no ponto de vista político ocorreu o inverso. A partir de então, verificou-se investimento maior na política partidária e na luta parlamentar por parte desses grupos. Para algumas regiões do interior da Bahia, como o Baixo-Médio São Francisco, a Revolução de 1930 restabeleceu antigas lideranças e consagrou o modus operandi dos coronéis, que continuaram sendo chefes locais e base de sustentação do novo governo (Melo, 1989: 101-110).

\section{ÀS URNAS: OS CORONÉIS E A ORGANIZAÇÃO PARTIDÁRIA PARA AS ELEIÇÕES DE 1933}

centralização do poder após a Revolução de 1930 não passava apenas pelo desar-
mamento dos coronéis no interior dos estados. Exigiam-se também profundas modificações nas instituições que davam sustentação a esse poder. Com base nisso, o governo que emergiu em 1930 tratava de ocupar os postos de mando nos municípios, reduto tradicional dos coronéis. No quadro da política vigente na Primeira República, o município constituía o principal obstáculo a um governo centralizado. No governo provisório, o papel do município continuava exigindo cuidados. Antes da nomeação de Juraci Magalhães para a interventoria da Bahia, por exemplo, o posto foi assumido por Leopoldo do Amaral (novembro de 1930/ 
fevereiro de 1931) e Artur Neiva (fevereiro de 1931/julho de 1931). Ambos enfrentaram forte crise política, tendo o último encabeçado uma reforma administrativa que visava minar as forças municipais. 0 interesse era dividir os limites políticos dos coronéis ao extinguir ou anexar determinadas localidades. As tensões geradas por essa proposta demonstram a força que detinham e que levaram à renúncia de Artur Neiva.

Assim, um dos principais objetivos da escolha de um oficial para assumir o governo baiano, após o fracasso de dois civis no posto de interventor federal, era pôr fim às disputas políticas que resistiram às armas vitoriosas de 1930 e implementar o programa revolucionário que em 11 meses acumulou conflitos, confrontos, boatos, mortes e perseguições políticas. Por isso, entende-se que a indicação de um nome de alguém indiferente aos bastidores da política doméstica para dirigir o estado, a exemplo do que ocorreu com Juraci Magalhães em setembro de 1931, serviu para aplacar os ânimos e garantiu o sucesso da implantação de parte do novo programa de governo na Bahia. Foi, portanto, uma manobra política de Vargas, que percebeu de imediato que a crise instalada entre os produtores e as lideranças políticas do estado não permitiria que um grupo remanescente da república deposta dirigisse a revolução na Bahia.

Juraci Magalhães chegou ao estado um pouco antes de a Revolução de Outubro completar um ano. Um jovem de 26 anos, com apenas sete meses de experiência em serviços administrativos, adquirida como auxiliar de Juarez Távora na sua tarefa de organização política, administrativa e social dos estados do Nordeste, o cearense que comandou uma das brigadas que invadira a Bahia no ano anterior chegava ao porto de Salvador, no dia 19 de setembro de 1931, para representar o governo federal no estado e tentar encerrar uma etapa conturbada do processo revolucionário: a interventoria de civis na Bahia.

Ainda que compartilhasse as ideias dos demais interventores dos estados vizinhos, que haviam recentemente criado o Bloco do Norte visando assegurar os interesses da região e apoiar o governo Vargas se este deliberasse o prolongamento da ditadura, Juraci Magalhães não hesitou em organizar seu lastro eleitoral na Bahia e cedo perscrutou os baianos da capital e do interior para a formação de uma base política. Ainda em janeiro de 1932, viajou para 14 municípios, com o objetivo de construir bases de sustentação do seu governo no interior do estado, sobretudo porque na Bahia, nesse período, o peso dos eleitores rurais e as forças políticas regionais ainda definiam os resultados eleitorais. De acordo com Paulo Silva, essas investidas no interior resultaram na formação de aliados fiéis e na aquisição, por parte de Juraci Magalhães, de notável conhecimento dos problemas do sertão (Silva, 2011: 29).

A essa altura, muitos coronéis já haviam sido reinvestidos nas chefias dos seus respectivos redutos. Conforme destacou Wilson Lins, eram homens que haviam deitado raízes no 
chão fecundo da afeição popular, em suas comunidades, razão pela qual foram aproveitados pelo tenente. Ao investigar essa reabilitação política dos coronéis no ano de 1932, Lins afirmou que "foi tal o papel desempenhado por esses chefes, na nova ordem política instalada no país, que será uma injustiça dizer que eles aderiram à Revolução, já que a Revolução é que havia aderido a eles" (Lins, 1979: 20).

0 apoio que Juraci Magalhães recebeu do interior do estado foi fundamental para o fortalecimento do governo provisório de Vargas. No ano de 1932, quando despontou em São Paulo o Movimento Constitucionalista, faç̧ões políticas da Bahia desalojadas do poder em 1930 ou descontentes com os rumos do novo governo, a exemplo de Seabra, que se afastou dos vitoriosos ainda em maio de 1931, organizaram-se em apoio a São Paulo. Além dos estudantes da Faculdade de Medicina, havia focos de descontentamento com o governo constituídos no interior do estado. Juraci Magalhães reprimiu violentamente essas manifestaç̃̃es de solidariedade com o apoio, mais um vez, de lideranças municipais, como Franklin Lins de Albuquerque, que em carta encaminhada a Juarez Távora em 15 de agosto de 1932 dizia estar a postos para atender ao chamado de Juraci Magalhães, podendo arregimentar de 8 a 10 mil homens "com pequena demora e dois mil prontos para marchar no primeiro momento" (Arquivo Juarez Távora. FGV/CPD OC.JT dpf.1930.05.00).

Para as lideranças desarmadas havia muita dificuldade para garantir apoio ao estado de São Paulo, por isso temia-se que mais uma vez elas fossem socorridas pelas forças mineiras. Em carta encaminhada a Otávio Mangabeira (1886-1960), ex-ministro das relações exteriores do governo deposto, que se encontrava no exílio, o baiano Euvaldo Pinho relatou que, se houvesse possibilidade de um homem político de prestígio seguir para o interior da Bahia, estava certo de que haveria um levante, principalmente porque lideranças das Lavras Diamantinas desejavam vingar a morte de Horácio de Matos (Mangabeira, 2012).

Em 1932, o coronel João Duque e outros do Vale do São Francisco estavam novamente em contato com lideranças mineiras, especialmente Artur Bernardes, que mantinha simpatias com a revolução paulista. Juraci Magalhães foi notificado da mobilização pelo serviço de informação e, contando já com o apoio de vários outros coronéis, a exemplo do Franklin Lins de Albuquerque, pôs fim aos planos de aproximação entre João Duque e Bernardes, impedindo que a Bahia saísse em apoio a São Paulo.

As lutas pela recomposição dos poderes eram intensas. Ainda ao final de 1932, coronéis de diferentes municípios baianos lançaram um documento definidor da política no interior do estado: o manifesto dos políticos sertanejos. De acordo com matéria publicada no jornal Diário da Bahia em 29 de novembro de 1932, era Franklin de Albuquerque quem liderava o grupo político do interior. Em entrevista ao jornal, o então representante das Lavras 
Diamantinas afirmou que desde o início do ano vinha organizando-se um movimento de coesão das forças políticas da região sanfranciscana. Segundo ele, não havia no estado, dentro de qualquer partido político, a comunhão de vistas como a que imperava entre os sertanejos do São Francisco. Tal como assegurou, todo aquele esforço estava destinado a apoiar Juraci Magalhães, com ou sem constituinte.

A Coligação Sertaneja, como veio a ser conhecida a reunião dessas lideranças, foi transformada num instrumento de ordenação política formalizada entre os coronéis do interior do estado. Ao todo, a Bahia abrigou seis coligações. Além da Coligação Sertaneja destacaram-se também a União dos Municípios do Nordeste Baiano, situada em Alagoinhas, e a Associação Social e Política Municipal, situada em Senhor do Bonfim. No conjunto, reivindicaram ao interventor o poder de arbitrar dissensões partidárias e pessoais e constituíram-se formalmente como órgão deliberativo para questões territoriais entre municípios, chegando a outorgarem-se funções de intervenção no desenvolvimento econômico e social (Machado Melo, 1989: 96-107).

Assim, embora Consuelo Sampaio tivesse afirmado que a divisão da Bahia era uma estratégia política de Juraci Magalhães para governá-la, com a subordinação dos coronéis que seriam disciplinados pelo Partido Social Democrático (PSD), que só viria a constituir-se em início de 1933, não se pode perder de vista o poder de articulação desses coronéis, liderados, como ficou explicitado na matéria, por Franklin Lins de Albuquerque. Afinal, data desse período a maior vigência política de alguns desses homens, a exemplo daqueles do Baixo-Médio São Francisco. 0 próprio Lins de Albuquerque mudou-se para a capital do estado e adquiriu um veículo de imprensa para melhor conduzir a política: 0 jornal O Imparcial.

Em carta endereçada a Getúlio Vargas no final de janeiro de 1933, Juraci Magalhães relatou ao governo provisório os passos que foram dados para a fundação do PSD na Bahia, segundo ele, uma assembleia constituída de 346 representantes municipais e distritais, "veIhos chefes sertanejos, muito dos quais nunca tinham comparecido a uma reunião política e outros jamais tinham vindo à capital" (Magalhães, 1982: 236).

A estratégia adotada por Juraci Magalhães para a fundação do partido oficial na Bahia foi marcada pelos princípios básicos da política da Primeira República, "compensando a adesão dos coronéis, com a concessão de benesses e favores que o poder Ihe permitia" (Sampaio, 1992: 92-93). Essas concessões, por sua vez, precisam ser lidas como um reconhecimento da força e da organização desses coronéis. Wilson Lins diria mais tarde: "Foi tal o papel desempenhado por esses chefes na nova ordem política instalada no país, que será uma injustiça dizer que aderiram à revolução, já que a Revolução é que havia aderido a eles" (Lins, 1979: 20). 
Dulce Pandolfi também identificou a interventoria de Juraci Magalhães como aquela, entre as demais dos estados do Nordeste, que mais se distanciou dos princípios defendidos pela Aliança Liberal e justificou essa conciliação com os setores oligárquicos baianos por ser a Bahia o estado onde eles detinham mais força política, mesmo depois do desarmamento levado a cabo logo após a revolução (Pandolfi, 1980: 354).

0 alinhamento dos coronéis do interior a Juraci Magalhães justifica-se também pelas características do sistema de governo centralizador adotado após a Revolução de 1930. Além do desarmamento das oligarquias locais, adotou-se uma legislação na qual os prefeitos passaram a ser nomeados e assistidos por um Conselho Consultivo. Estabeleceu-se também "um sistema de recursos que subia do prefeito ao interventor e deste ao chefe do governo nacional", retirando a autonomia do município (Leal, 2012: 94).

Dentro desse novo modelo, o alinhamento com o interventor federal no estado era a única maneira de lideranças políticas do interior conseguirem melhorias para os seus respectivos redutos, uma vez que as arrecadações municipais eram ínfimas. No entanto, é preciso destacar que a emergência de um Estado forte esteve intimamente relacionada a um jogo de poder, e a sua consolidação não foi imediata. No pós-1930, o Estado ficou representado por diferentes grupos sociais, o que significava estar assentado num equilíbrio de forças contraditórias visivelmente insustentável (Weffort, 1980: 44).

Assim, nos primeiros anos após a Revolução de 1930, grupos políticos e econômicos com interesses e ideias por vezes conflitantes buscaram (re)conciliações. Por meio dos interventores, Vargas tentou unificar as forças estaduais, integrar os estados na revolução e implementar o projeto revolucionário, visando à centralização política (Gomes, 1986: 30). Estes, por sua vez, na correlação de forças com grupos políticos e econômicos locais, e até mesmo com grupos sociais de menor força política, não raro precisaram recorrer à reconciliação e a acomodações políticas, obtendo sucesso à medida que atendiam a algumas exigências desses grupos, sem o que jamais teriam condições de dar suporte ao projeto centralizador de Vargas.

\section{CONCLUSÃO}

Dara Aspásia Camargo, o pacto agrário que se renovou após 1930 não era "simples re-
sultante de poder residual das oligarquias" mas um acordo deliberado que eliminava alguns de seus recursos políticos enquanto ampliava outros. Assim, o processo de centralização política que esvaziava, em parte, o poder de determinadas oligarquias, destruindo as suas manifestações de autonomia, operava-se "com a ajuda desse mesmo poder oligárquico, graças às cisões que dividem internamente as elites regionais e que as levam a competir pelos favores do Estado". Essa predisposição aos acordos seria habilmente utilizada pelo poder 
central na Bahia, no caso, Juraci Magalhães, e permitiu-lhe "substituir as velhas máquinas oligárquicas da República deposta por outras mais permeáveis aos novos objetivos nacionais dentro de uma estratégia global de centralização política" (Camargo, 1983: 15).

As associações de municípios na Bahia podem ser vistas à luz desse conturbado processo. 0 apoio dado pelos coronéis e produtores do interior ao novo interventor não pode ser lido apenas como subordinação, tampouco como puro e simples adesismo à revolução. Muitos desses homens estiveram dispostos a negociar, mas a negociação foi também pautada por eles. Percebe-se que não coube apenas a Juraci Magalhães, quase um ano após a vitória revolucionária, chegar à Bahia e convencer os coronéis do interior a apoiar a sua gestão do estado, tal como parecem querer nos convencer os seus livros de memória (Magalhães, 1982). O contrário pode servir como uma via alternativa para entender o sucesso que ele teve como interventor no estado.

0 processo de reconciliação entre Juraci Magalhães e as oligarquias locais, bem como as concessões decorrentes desse processo, certamente foram o que conferiu ao PSD a maioria dos votos nas eleições de 1933, visto que o poder de barganha da oposição era infinitamente menor. Somente resgatando as atuações desses homens do interior é que podemos ter um quadro mais completo da Revolução de 1930 na Bahia e, por extensão, em todo o Brasil.

\section{REFERÊNCIAS BIBLIOGRÁFICAS}

ALMANAK LAEMMERT. Anuario commercial, Industrial, Agricola, Profissional e Administrativo da capital Federal e dos Estados Unidos do Brasil. Estados do Norte. Rio de Janeiro: Empresa Almanak Laemmert Ltda, 1930. v. 3, p. 226-362. Disponível em: <http://memoria.bn.br/DocReader/Hotpage/HotpageBN. aspx?bib=313394\&pagfis=103498\&url=http://memoria.bn.br/docreader\#>. Acesso em: 23 abr. 2018.

ARQUIVO JUAREZ TÁVORA. FGV/CPDOC.JT dpf.1930.05.0.

BATISTA, E. E. A Bahia para os baianos: acomodação e reação política ao governo de Getúlio Vargas (19301937). Tese (Doutorado em História) - Programa de Pós-Graduação em História, Universidade Federal da Bahia, Salvador, 2018.

CAMARGO, A. A revolução das elites: conflitos regionais e centralização política. In: A Revolução de 30: seminário realizado pelo Centro de Pesquisa e Documentação de História Contemporânea do Brasil (CPDOC). Setembro de 1980. Brasília, DF: Editora UnB, 1983. p. 7-46.

DE DECCA, E. S. 1930, O silêncio dos vencidos: memória, história e revolução. São Paulo: Brasiliense, 2004.

FAUSTO, B. A Revolução de 1930. In: MOTA, C. G. Brasil em perspectiva. 20. ed. Rio de Janeiro: Bertrand, 1995. p. 227-255.

FERREIRA, M. M.; PINTO, S. C. S. A crise dos anos 1920 e a Revolução de 1930. In: FERREIRA, J.; DELGADO, L. A. N. (orgs.). O tempo do liberalismo excludente - da Proclamação da República à Revolução de 1930. 7. ed. Rio de Janeiro: Civilização Brasileira, 2014. p. 387-415. 
FRANCO, V. A. M. Outubro de 1930. 5. ed. Rio de Janeiro: Nova Fronteira, 1980. (1ª ed. 1931).

GOMES, Â. C. Confronto e compromisso no processo de constitucionalização (1930-1935). In: FAUSTO, B.; HOLANDA, S. B. História geral da civilização brasileira - III. O Brasil republicano: sociedade e política (1930-1964), volume 10. Rio de Janeiro: Difel, 1986. p. 13-94.

LEAL, V. N. Coronelismo, enxada e voto: o município e o regime representativo no Brasil. 7. ed. São Paulo: Companhia das Letras, 2012.

LIMA SOBRINHO, B. A verdade sobre a Revolução de outubro - 1930. 2. ed. São Paulo: Alfa-Ômega, 1975.

LINS, W. Mandonismo e obediência. In: LINS, W.; TEIXEIRA, C.; FALCON, G.; MACHADO MELO, M. A. Coronéis e oligarquias. Salvador: Universidade Federal da Bahia; Ianamá Editora, 1979. p. 7-28. (Cadernos de Educação Política).

MACHADO MELO, M. A. História política do Baixo Médio São Francisco: um estudo de caso de coronelismo. Dissertação (Mestrado) — Programa de Pós-Graduação em História, Universidade Federal da Bahia, Salvador, 1989.

MAGALHÃES, J. Minhas memórias provisórias. Depoimento prestado ao CPDOC. Rio de Janeiro: Civilização Brasileira, 1982. (Coordenadora Alzira Alves de Abreu).

MANGABEIRA, 0. Cartas do exílio (1930-1934). Salvador: Fundação Pedro Calmon, 2012. v. 1. (Organização Consuelo Novais Sampaio).

MELO, M. A. M. História política do baixo-médio São Francisco: um estudo de caso de coronelismo. Dissertação (Mestrado em História) - Universidade Federal da Bahia, Salvador, 1989.

OLIVEIRA, L. L. Revolução de 1930: uma bibliografia comentada. BIB - Revista Brasileira de Informação Bibliográfica em Ciências Sociais, São Paulo, n. 4, p. 95-116, 1978.

PANDOLFI, D. C. A trajetória do norte: uma tentativa de ascenso político. In: GOMES, Â. M. C. Regionalismo e centralização política. Rio de Janeiro: Nova Fronteira, 1980. p. 338-425.

PANG, E.-S. Coronelismo e oligarquias (1889-1934): a Bahia na Primeira República Brasileira. Tradução de Vera Teixeira Soares. Rio de Janeiro: Civilização Brasileira, 1979.

SAMPAIO, C. N. Poder e representação: o Legislativo da Bahia na Segunda República, 1930-1937. Salvador: Assembleia Legislativa; Assessoria de Comunicação Social, 1992.

SAMPAIO, C. N. Os partidos políticos da Bahia na Primeira República: uma política de acomodação. Salvador, Editora da Universidade Federal da Bahia, 1998.

SARMENTO, S. N. A raposa e a águia. J. J. Seabra e Rui Barbosa na política baiana da Primeira República. Salvador: EDUFBA, 2011.

SILVA, J. C. B. A Revolução de 1930 na Bahia. (Documento e Estudo). Dissertação (Mestrado em Ciências Sociais) - Universidade Federal da Bahia, Salvador, 1981.

SILVA, P. S. Âncoras de tradição: luta política, intelectuais e construção do discurso histórico na Bahia (1930/1949). Salvador: EDUFBA, 2011.

TAVARES, L. H. D. História da Bahia. 11. ed. rev. ampl. São Paulo: Editora UNESP; Salvador: EDUFBA, 2008. 
VISCARDI, C. M. R. O teatro das oligarquias: uma revisão da "política do café com leite". Belo Horizonte: Fino Traço, 2019. E-book.

WEFFORT, F. C. O populismo na política brasileira. Rio de Janeiro: Paz e Terra, 1980. 